\title{
Osseous manifestations of non-Hodgkin's lymphoma in Human Immunodeficiency Virus (HIV) infection and Acquired Immunodeficiency Syndrome (AIDS)
}

\author{
R Magagula MBChB(Medunsa) \\ MN Rasool MBChB(Natal), FCS(Ortho), PhD \\ PK Ramdial MBChB(Natal), FCPath(Anat) \\ Y Singh MBChB(Medunsa),FCPath(Anat) \\ A Ramburan MMed Sci(Anat Path), PhD \\ Medical Scientist, Inkosi Albert Luthuli Central Hospital, Durban \\ Corresponding author: \\ Dr R Magagula \\ Department of Orthopaedics Surgery \\ Inkosi Albert Luthuli Central Hospital \\ 800 Vusi Mzimela Road \\ 4091 Cato Manor \\ Email: richmag4250@yahoo.com \\ Tel: +2731 2401000 ext 2166 \\ Fax: +27312401089
}

Registrar in Orthopaedic Surgery, University of KwaZulu-Natal, Durban

Acting Head of Department, Orthopaedic Surgery, University of KwaZulu-Natal, Durban

Head of Department, Anatomical Pathology, Inkosi Albert Luthuli Central Hospital, Durban

Anatomical Pathologist, Inkosi Albert Luthuli Central Hospital, Durban

\begin{abstract}
Background: Lymphoma is the second most common Acquired Human Immunodeficiency Syndrome (AIDS)associated neoplasm, the commonest being Kaposi sarcoma. The diagnosis and treatment of bone lymphoma still remains a challenge in our environment.

Materials and methods: This is a retrospective chart review of 105 patients who were diagnosed histopathologically with lymphoma involving the bone over a period of 11 years in six local hospitals.

Results: Forty-five (42.9\%) patients with bone lesions and who were positive for Human Immunodeficiency Virus (HIV) formed the cohort. Clinical manifestations varied from swelling and pain in all patients to pathological fractures $(n=5,11.1 \%)$ and paraplegia $(n=11,24.4 \%)$ due to cord compression. Common sites included the spine, pelvis, femur, humerus, ribs, tibia and mandible. Treatment included chemotherapy and radiation, splinting or surgical fixation of pathological fractures and decompression of the spine with or without fusion.

Conclusion: Bone lymphoma should be considered in any HIV-positive patient presenting with unexplained swelling and pain. The radiological picture may mimic bone infections like chronic pyogenic osteomyelitis, tuberculosis and fungal infections, other systemic disorders like Paget's disease, blood-related tumours such as leukaemia and other primary and metastatic bone neoplasms.
\end{abstract}

Key words: bone lymphoma, non-Hodgkin's, HIV, AIDS 


\section{Introduction}

Lymphoma, commonly associated with congenital and acquired immune deficiency, is the second most common neoplasm associated with HIV and AIDS, and nonHodgkin's lymphoma (NHL) is an AIDS-defining condition according to the World Health Organisation (WHO). ${ }^{1,2}$ With more than six million South Africans infected with HIV and 60 per cent of them already receiving highly active antiretroviral therapy (HAART), HIV-associated morbidity and mortality have decreased significantly. ${ }^{3}$ However, the incidence of AIDS-related lymphoma has not decreased as much and remains a major therapeutic problem. ${ }^{3}$ Skeletal manifestations of this entity in patients with HIV infection are rarely reported in the literature. Any bone, except small bones of hands and feet, can be involved and radiological manifestations are variable making diagnosis difficult and sometimes missed. ${ }^{4}$ This is a retrospective review of clinical records and radiographs of patients who were HIV-positive and diagnosed with lymphoma affecting bone either as primary or secondary involvement. The aim is to highlight the spectrum of bone lesions in NHL and increase awareness of its occurrence in patients with HIV infection.

\section{Materials and methods}

The medical records of all patients who were diagnosed histopathologically with lymphoma involving the musculoskeletal system seen from September 2002 to December 2013 in six local hospitals were reviewed retrospectively. The clinical data recorded included clinical presentation, age, gender, HIV status, antiretroviral treatment, laboratory analysis and CD-4 count. Work-up of these patients included blood analysis (full blood count and differential, erythrocyte sedimentation rate, C-reactive protein, liver enzymes and calcium, magnesium and phosphate). Imaging included computerised tomograph of the chest, ultrasound of the abdomen and bone scan. The radiological patterns of bone lymphoma were assessed on plain radiographs mainly, and on magnetic resonance scans (MRI) when the spine was involved. Open biopsy of the most accessible lesion was performed to confirm the diagnosis. All HIV patients who presented with lymphoma involving bone either as primary or secondary lesions were included. The patients were classified according to the World Health Organisation (WHO) into four groups: ${ }^{1}$

1. Lymphoma with a single bone site with or without regional lymph node involvement

2. Lymphoma with multiple bones involved, but no visceral or lymph node involvement

3. Bone lymphoma and involvement of other visceral sites or multiple lymph nodes at multiple sites on clinical work-up

4. A patient is diagnosed with extra-osseous lymphoma and bone involvement is identified during work-up
Groups 1 and 2 are considered primary bone lymphomas and groups 3 and 4 are secondary bone involvement. Patients who were either HIV-negative or with unknown immune status were excluded.

\section{Results}

In a period of 11 years, 105 patients were diagnosed histologically with lymphoma involving bone. Of these 45 $(42.9 \%)$ were confirmed HIV-positive and had lymphoma. Their ages ranged from 5 to 60 years (mean 24.4) (Figure 1).

Lymphoma is an AIDS-defining condition according to the World Health Organisation

There was no significant male:female difference. All patients presented with constitutional symptoms, pain and swelling, pathological fractures $(n=6,13.3 \%$, two of which were in one patient) and paraplegia $(\mathrm{n}=11,24.4 \%)$ (Table I). The spine was by far the most commonly involved area $(\mathrm{n}=23,51.1 \%)$ (Table II). The thoracic $(\mathrm{n}=12$, $52.2 \%$ ) region was most often involved, followed by the lumbar $(n=8,34.8 \%)$ and cervical spine $(n=3,13.0 \%)$. Other sites included the pelvis, femur, ribs, humerus, tibia and mandible. Fifty-eight per cent $(n=26)$ of the patients presented with secondary bone lymphoma and forty-two per cent $(n=19)$ were primary. The majority of the patients had anaemia of chronic illness (haemoglobin ranged from $6.5 \mathrm{~g} / \mathrm{dL}$ to $13.5 \mathrm{~g} / \mathrm{dL}$, mean 9.04), were malnourished and presented with raised erythrocyte sedimentation rate (ESR) (ranged from $17 \mathrm{~mm} / \mathrm{hr}$ to 143 $\mathrm{mm} / \mathrm{hr}$, mean 65 ). The absolute CD4 count in $77.8 \%$ ( $\mathrm{n}=$ 35) of the patients was below 200 (Table III). All patients had large B-cell non-Hodgkin's lymphoma, with CD10 immunopositivity.

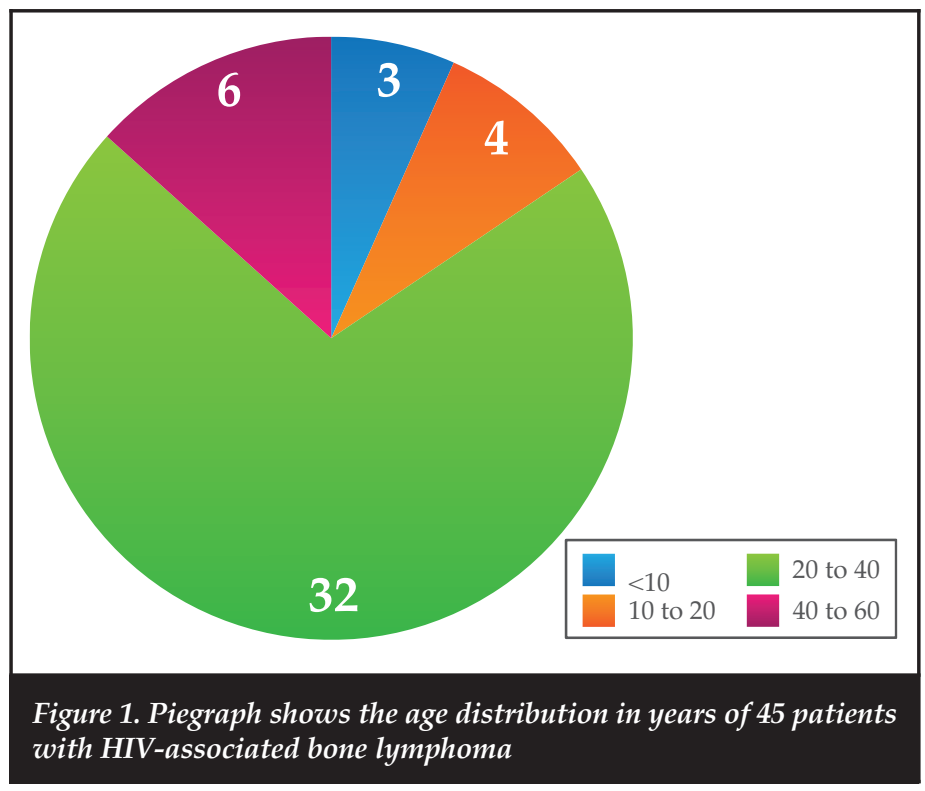




\begin{tabular}{|c|c|}
\hline Symptoms & Patients \\
\hline Loss of weight, malaise, loss of appetite & 45 \\
\hline Pain & 45 \\
\hline Swelling & 9 \\
\hline Weakness & 5 \\
\hline Pathological fracture (long bones) & $6^{*}$ \\
\hline Paraplegia (vertebral) & 11 \\
\hline
\end{tabular}

\begin{tabular}{|l|r|r|r|r|}
\multicolumn{4}{|c|}{ Table II: Anatomical locations of lesions and the types of lymphoma } \\
\hline Sites & $\begin{array}{r}\text { Number of } \\
\text { bones } \\
\text { involved }\end{array}$ & $\begin{array}{r}\text { Percentage } \\
\text { of total } \\
(\%)\end{array}$ & $\begin{array}{r}\text { Primary } \\
\text { bone } \\
\text { lymphoma }\end{array}$ & $\begin{array}{r}\text { Secondary } \\
\text { involvement }\end{array}$ \\
\hline Vertebrae & 23 & 51.1 & 8 & 15 \\
\hline Ribs & 6 & 13.3 & 0 & 6 \\
\hline Humerus & 4 & 8.8 & 3 & 1 \\
\hline Pelvis & 3 & 6.6 & 1 & 2 \\
\hline Femur & 3 & 6.6 & 2 & 1 \\
\hline Mandible & 3 & 6.6 & 3 & 0 \\
\hline Tibia & 2 & 4.4 & 2 & 0 \\
\hline Clavicle & 1 & 2.2 & 0 & 1 \\
\hline
\end{tabular}

Table III: Absolute CD4 count and antiretroviral therapy at the time of diagnosis of lymphoma

\begin{tabular}{|l|r|r|r|}
\hline \multirow{2}{*}{ CD4 count } & $\begin{array}{r}\text { Number of } \\
\text { patients }\end{array}$ & \multicolumn{2}{c|}{ Hes } \\
\hline$<50$ & 9 & 6 & 3 \\
\hline $50-100$ & 15 & 12 & 3 \\
\hline $100-200$ & 11 & 4 & 7 \\
\hline $200-300$ & 3 & 1 & 2 \\
\hline $300-400$ & 4 & 2 & 2 \\
\hline $400-500$ & 1 & 0 & 1 \\
\hline$>500$ & 2 & 1 & 1 \\
\hline
\end{tabular}

Treatment was multidisciplinary and included orthopaedics, neurosurgery and haematology/oncology
Imaging investigations revealed a subtle or 'near normal' pattern $(\mathrm{n}=7,15.5 \%)$, lytic destructive $(\mathrm{n}=18,40 \%)$, sclerotic $(\mathrm{n}=12,26.7 \%)$, mixed lytic and sclerotic $(\mathrm{n}=8$, $17.8 \%$ ). Pathological fractures were present in five (50\%) long bones and the periosteal reaction was mostly nonspecific. In the appendicular skeleton the lesions were monostotic $(n=11,84.6 \%)$ and polyostotic $(n=2,14.3 \%)$ and in the axial skeleton they were single level $(\mathrm{n}=7$, $31.8 \%)$ and multi-level $(\mathrm{n}=15,68.2 \%)$ vertebral involvement (Figures 2-6).

Treatment was multidisciplinary and included orthopaedics, neurosurgery and haematology/oncology.

All patients received $\mathrm{CHOP}$ regimen chemotherapy (cyclophosphamide, doxorubicin, vincristine and prednisolone) except for four $(8.9 \%)$ patients who died of pneumonia after biopsy while awaiting histology results and referral to oncology. Nine patients $(20 \%)$ did not complete the minimum of six cycles of chemotherapy because they became very debilitated and abandoned therapy and demised after 3 months. Twenty patients $(44.5 \%)$ received a combination of chemotherapy and radiotherapy.

Most long bone pathological fractures were treated surgically in adults [plating of the humerus $(n=1,16.6 \%)$ and intermedullary nailing of the femur $(\mathrm{n}=2,33.3 \%)$ ] and immobilised in a plaster in children $(\mathrm{n}=2,33.3 \%)$. One femoral $(16.6 \%)$ nail was later removed and an external fixator applied after development of deep infection post-operatively and the patient demised 2 months later due to septicaemia. Two patients $(33.3 \%)$ with pathological fractures of the femur and humerus were treated with skeletal traction and backslab immobilisation, respectively, because they were not fit for surgery. They demised of complications 4 weeks later.

Patients who presented with cord compression were treated by surgical decompression with or without spinal fusion (decompression alone, $\mathrm{n}=8,34.8 \%$ and decompression and fusion $\mathrm{n}=6,26.1 \%$ ). Within the first 18 months of treatment a total of $28(62.2 \%)$ patients had demised. Currently five $(11.1 \%)$ patients have been disease-free for 2 years, seven $(15.6 \%)$ have had recurrence, and five $(11.1 \%)$ are lost to follow-up. The minimum follow-up was 6 months (range: 6 months to 2 years; mean: 12 months).

\section{Discussion}

Reports on bone lymphoma in HIV-positive patients are rare in the literature, with the exception of a few case

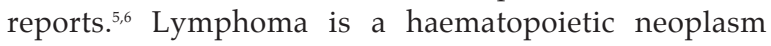
composed of malignant lymphoid cells affecting different parts of the body. The most common areas of involvement include lymph nodes, spleen, central nervous system, bone marrow and gastrointestinal tract. Malignant lymphomas are classified as Hodgkin's lymphoma (the pathognomonic feature being the presence of ReedSternberg cells) and non-Hodgkin's lymphoma. ${ }^{1,2,7}$ 


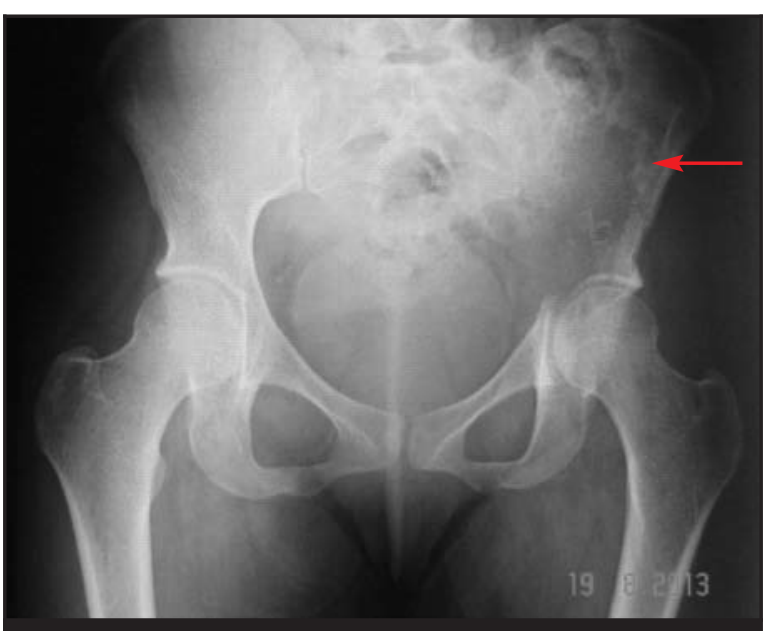

Figure 2. AP view of the pelvis (arrow) showing a large lytic area with destruction of the left ilium in a 27-yearold woman with secondary NHL

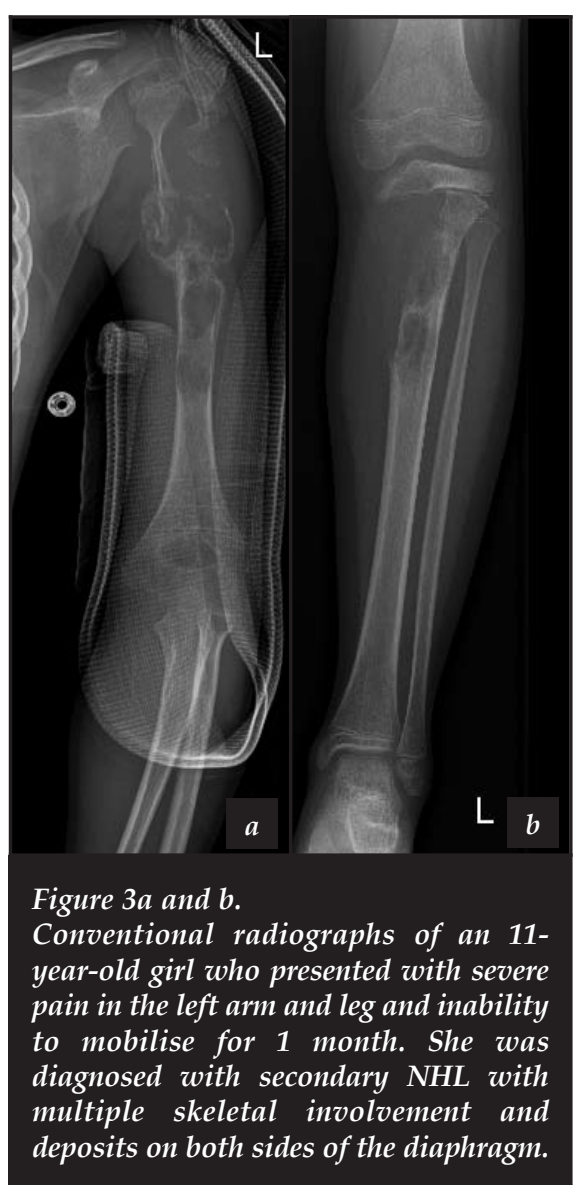

In our series all patients had diffuse large B-cell NHL
The current World Health Organisation (WHO) classification of non-Hodgkin's lymphoma (NHL) is based mainly on the B-cell and T-cell origins of the neoplasm. ${ }^{1}$ In HIV infection the majority of these lymphomas are highgrade B-cell lymphoma: Burkitt lymphoma, diffuse large B-cell lymphoma and diffuse large B-cell lymphoma with immunoblastic features. ${ }^{78}$ In our series all patients had diffuse large B-cell NHL.

Primary bone lymphoma (PBL), first reported in the English-language literature by Parker and Johnson in 1939 , is a rare disease, accounting for approximately $3 \%$ of all primary bone malignancies and $4 \%$ to $7 \%$ of all extranodal lymphomas. ${ }^{913}$ The low incidence of PBL underpins the controversies associated with definition, management strategies and prediction of outcome. ${ }^{11}$ The common sites of bone involvement include the ribs, pelvis, sternum, clavicle, femur, humerus and vertebrae. ${ }^{1,7}$ It is therefore unusual to find lymphoma involving the small bones of the hands and feet. ${ }^{1}$

NHL is present in about $1 \%$ to $3 \%$ of HIV-seropositive patients at the time of initial diagnosis of HIV infection. ${ }^{2}$ The HIV is not involved in the malignant transformation of B cells since no HIV sequences have been detected in the lymphoma cells. ${ }^{14}$ However, the HIV infection induces the production of a variety of cytokines and growth factors that play an important role in the activation and differentiation of B cells. ${ }^{14,15}$ In AIDS-associated Burkitt lymphoma (BL), which accounts for 30 per cent of all cases of AIDSassociated lymphomas, the molecular lesions involve activation of myelocytomatosis cancer oncogene ( $c M Y C$ ) and inactivation of tumour suppressor protein (P53). 10,14,16

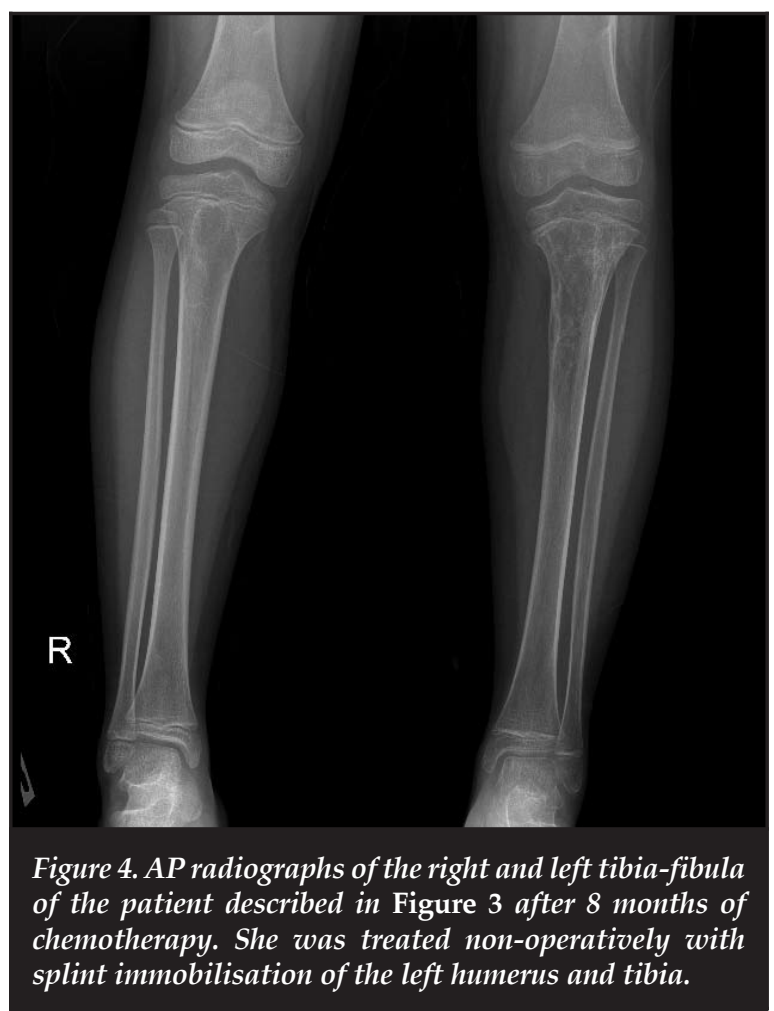


NHL is present in about $1 \%$ to $3 \%$ of $\mathrm{HIV}$-seropositive patients at the time of initial diagnosis of HIV infection
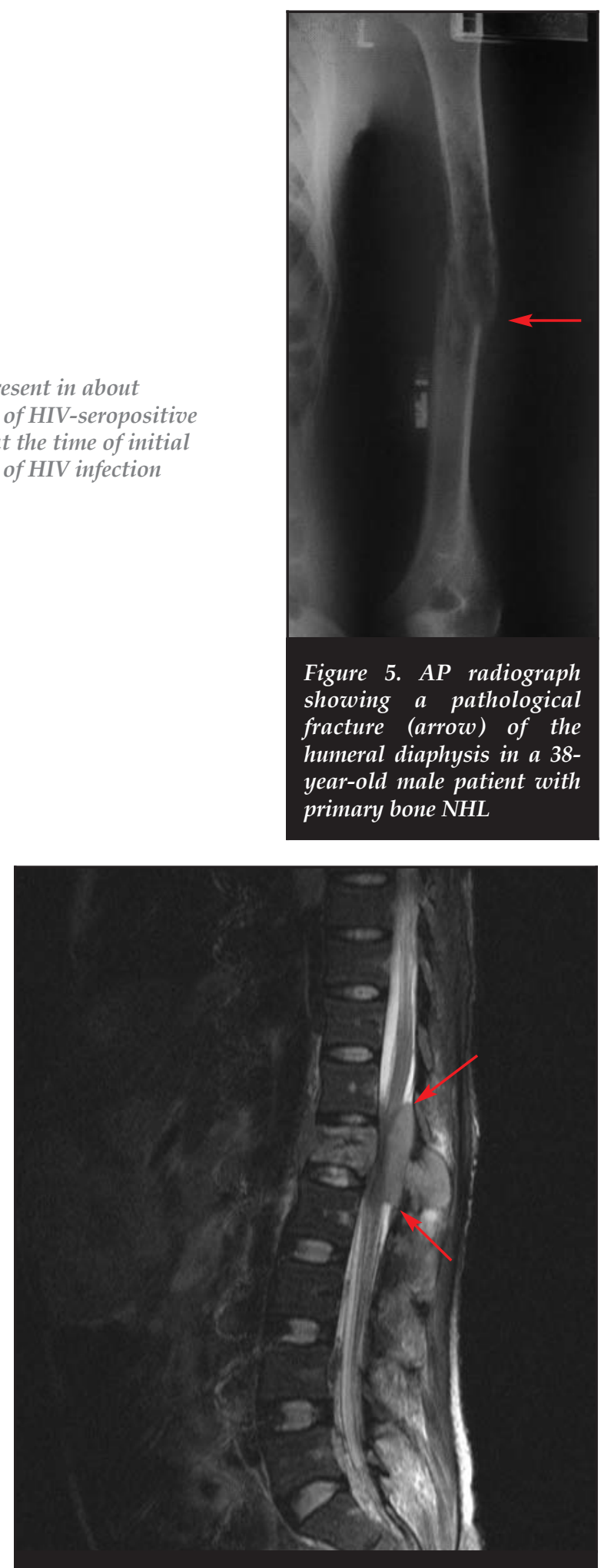

Figure 6. T2-weighted MRI shows a collapse of L1 in a 30-year-old woman with secondary NHL who presented with complete paraplegia. A large extradural mass (arrows) extends from T12 vertebral body to L2. There is marked stenosis and cord compression at this level.
With AIDS-associated large B-cell lymphoma (LBL) the molecular alterations involve deregulation of the $B C L-6$ proto-oncogene. ${ }^{14}$ There is strong evidence suggesting that Epstein-Barr virus (EBV) and human herpes virus 8 (HHV8) infections are implicated in the pathogenesis of both AIDS-associated BL and LBL..$^{10,16-18}$

Radiological features are quite variable and somewhat non-specific. ${ }^{1,4}$ The lytic destructive pattern (Figure 2 ) is the most common radiological presentation. ${ }^{5,17}$ This pattern may be described as 'permeative', 'moth-eaten' or 'geographic' with well-defined margins., ${ }^{2,7}$ The blastic sclerotic pattern is more common in secondary bone lymphoma. ${ }^{4}$ Often the lesion is a mixture of sclerotic and lytic patterns. ${ }^{1}$ Subtle or 'near-normal' radiographic pattern may need magnetic resonance imaging (MRI) or bone scintigraphy to assess the pathology. ${ }^{4}$ The process is often poorly demarcated with a large area of transition from normal bone. ${ }^{1}$ In long bones the diaphysis tends to be preferentially involved; however, the metaphysis may also be involved (Figures 3 and 5). Cortical break may be accompanied by a large soft tissue mass. Periosteal reaction is unusual and non-specific. Lesions can be solitary or polyostotic. ${ }^{1}$ In the spine, bone lymphoma is characterised by involvement of both vertebral bodies and posterior elements. ${ }^{17}$ There is usually a large extradural mass with canal stenosis and cord compression (Figure 6). All the above radiological patterns were observed in this study.

CT scan may be more sensitive than conventional radiography for cortical breakthrough, but its main role is ruling out the presence of nodal disease or other soft tissue involvement in the chest and abdomen. ${ }^{4} \mathrm{MRI}$ is useful to assess the extent of bone marrow and soft tissue involvement as well as the status of the spinal cord. Bone marrow shows low signal intensity on T1-weighted sequences and high signal intensity on T2-weighted images. ${ }^{4,19}$ Bone scintigraphy always shows an increased uptake and is useful for demonstrating multifocal bone involvement. ${ }^{4,7}$

Bone lymphoma can resemble various conditions which can make the diagnosis difficult and delayed. ${ }^{1}$ Some of these conditions include bone infections (chronic pyogenic osteomyelitis, tuberculosis, fungal), systemic conditions like Paget's disease, primary bone malignancies (e.g. osteosarcoma, Ewing sarcoma, leukaemias) and metastatic deposits like in prostatic cancer. Definitive diagnosis is established on biopsy. ${ }^{3,4,8}$

Lymphoma in HIV is more widespread and presents with extensive organ involvement than in the HIVnegative population. ${ }^{7}$ Traditional treatment modalities include chemotherapy alone or in combination with irradiation therapy. ${ }^{13}$ The CHOP regimen is considered the minimum standard of care. ${ }^{20}$ The patient receives six to eight cycles every three weeks as an outpatient. Antiretroviral therapy is an important part of management. Response is assessed by plain radiographs (Figure 4) and PET scan. 
The outcome for NHL in the setting of HIV continues to improve as insights into the pathology and treatment advance. ${ }^{21,22}$ Awareness of clinical manifestations and the various patterns of bone involvement in HIV/AIDS is important in making the diagnosis.

\section{Conclusion}

Bone lymphoma should be considered in any HIVpositive patient presenting with unexplained swelling and pain. Despite the concerted drive to control HIV disease, lymphoma is still one of the most common HIV-related malignancies. ${ }^{3,21}$ The mortality rate in our study was $62.2 \%$ $(\mathrm{n}=28)$, probably owing to patients being referred late from peripheral hospitals and bone lesions are not suspected early. Some of the poor prognostic factors observed in this study included low absolute CD4 count and number of extra-nodal sites involved.

The authors did not receive payments directly or indirectly from a third party in support of any aspect of this work.

Conflict of interest: none.

\section{References}

1. Fletcher CDM, Unni KK, Mertens F (Eds): WHO classification of tumours. Pathology and genetics of soft tissue and bone. IARC Press: Lyon,2002;304-308.

2. Ioachim $\mathrm{Hl}$, Medeiros LJ, Ioachim S. Lymph node pathology. Fourth Edition, Lippincott, Williams and Wilkins, 563-67.

3. Opie J. Haematological complications of HIV infection.S Afr Med J, 2012;102:465-68.

4. Suleman FE, Bellew N. Primary bone lymphoma: Imaging findings of a rare primary bone tumour. SA Ortho J, 2011;10:68-70.

5. Aboulafia AJ, Khan F, et al. AIDS-associated secondary lymphoma of bone: a case report with review of the literature. J of Clin Oncol, 1998;27:128-34.

6. Sandkovsky U, Martin PF, Bissio E. Non-Hodgkin lymphoma of bone in an HIV-infected patient from Argentina. J Infect Dev Ctries 2011;5(11):815-19.

7. Bullough P. Orthopaedic Pathology. Fourth Edition, Mosby, 475-77.

8. Wiggill TM, Mayne ES, Willem P. Challenges in lymphoma diagnosis in HIV positive patients in the South African setting. Transfus Apher Sci. 2013;49:157-62.

9. Parker F, Jackson H. Primary reticulum cell sarcoma of bone. Surg Gyne Obstet 1939;68:45.
10. Carbone A, Gloghini A. AIDS-related lymphomas: From pathogenesis to pathology. Brit J of Hem, 2005;130:662-70.

11. Maruyama D, Watanabe T et al. Primary bone lymphoma: a new detailed characterization of 28 patients in a singleinstitution study. Jpn J Clin Oncol 2007;37:216-23.

12. Bhagavathi $S$, Micale MA, et al. Primary bone diffuse large B-cell lymphoma; clinicopathologic study of 21 cases and review of literature. Am J Surg Pathol 2009: 33:1463-69

13. Ramadan KM, Shenkier $\mathrm{T}$, et al. A clinicopathological retrospective study of 131 patients with primary bone lymphoma: a population-based study of successively treated cohorts from the British Columbia cancer Agency. Ann of Oncol 2007;18:129-35.

14. Gaidano G, Carbone A, et al. Pathogenesis of AIDS-related lymphomas. Am J Pathol 1998;152:623-30.

15. Emilie D, Zou W, et al. Production and role of IL-6, IL-10 and IL-13 in B-lymphocyte malignancies and in Blymphocyte hyperactivity of HIV infection and Autoimmunity. Blood, 1997;11:133-42.

16. Nakamura H, Said JW, et al. Mutation and protein expression of p53 in Acquired Immunodeficiency Syndrome-related Lymphomas. Blood 1993:82:920-26.

17. Dong HY, Scadden DT, et al. Plasmablastic lymphoma in HIV-positive patients: an aggressive Epstein-Barr Virusassociated extramedullary plasmacytic neoplasm. Am J Pathol 2005;29:1633-41.

18. Ballerini P, Gaidano G, et al. Multiple genetic lesions in Acquired Immunodeficiency Syndrome-related nonHodgkin's Lmphoma. Blood, 1993;81:166-76.

19. Krishan A, Shirkoda A, et al. Primary bone lymphoma: Radiographic-MRI imaging correlation. Radiographs 2003;23:1371-87.

20. Beal K, Allen L, Yahalom J. Primary bone lymphoma: treatment results and prognostic factors with long-term follow-up of 82 patients. Cancer 2006;106:2652-56.

21. Lim ST, Levine AM. Recent advances in acquired immunodeficiency syndrome (AIDS)-related lymphoma. CA Cancer J Clin 2005;55:229-41.

22. Noy A. Update on HIV lymphoma. Curr Oncol Rep 2007 Sep;9:384-90.

This article is also available online on the SAOA website (www.saoa.org.za) and the SciELO website (www.scielo.org.za). Follow the directions on the Contents page of this journal to access it. 